\title{
Effects of Allogeneic Hematopoietic Stem Cell Transplantation Plus Thymus Transplantation on Malignant Tumors: Comparison Between Fetal, Newborn, and Adult Mice
}

\author{
Yuming Zhang, ${ }^{1,2,{ }^{*}}$ Naoki Hosaka, ${ }^{1, *}$ Yunze Cui, ${ }^{3,4}$ Ming Shi, ${ }^{3}$ and Susumu Ikehara ${ }^{3}$
}

We have recently shown that allogeneic intrabone marrow-bone marrow transplantation + adult thymus transplantation (TT) is effective for hosts with malignant tumors. However, since thymic and hematopoietic cell functions differ with age, the most effective age for such intervention needed to be determined. We performed hematopoietic stem cell transplantation (HSCT) using the intrabone marrow method with or without TT from fetal, newborn, and adult B6 mice $\left(\mathrm{H}-2^{\mathrm{b}}\right)$ into BALB/c mice $\left(\mathrm{H}-2^{\mathrm{d}}\right)$ bearing Meth-A sarcoma $\left(\mathrm{H}-2^{\mathrm{d}}\right)$. The mice treated with all types of HSCT + TT showed more pronounced regression and longer survival than those treated with HSCT alone in all age groups. Those treated with HSCT + TT showed increased numbers of CD4 $4^{+}$and CD8 ${ }^{+}$ T cells but decreased numbers of Gr-1/Mac-1 myeloid suppressor cells and decreased percentages of FoxP3 cells in $\mathrm{CD}^{+} \mathrm{T}$ cells, compared with those treated with HSCT alone. In all mice, those treated with fetal liver cell (as fetal HSCs) transplantation + fetal TT or with newborn liver cell (as newborn HSCs) transplantation (NLT) + newborn TT (NTT) showed the most regression, and the latter showed the longest survival. The number of Gr-1/Mac-1 cells was the lowest, whereas the percentage of $\mathrm{CD}_{2} 2 \mathrm{~L}^{-} \mathrm{CD} 44^{+}$effector memory $\mathrm{T}$ cells and the production of interferon $\gamma($ IFN- $\gamma)$ were highest in the mice treated with NLT + NTT. These findings indicate that, at any age, HSCT + TT is more effective against cancer than HSCT alone and that NLT + NTT is most effective.

\section{Introduction}

A LLOGENEIC BONE MARROW transplantation (BMT) has been used to treat not only leukemias, immunodeficiencies, and autoimmune diseases but also solid malignant tumors [1,2], as the graft versus tumor effect induced by its alloreactivity can be anticipated in the case of malignant tumors. Although donor lymphocyte infusion is used for this purpose [3,4], graft versus host disease (GVHD), which is one of the major lethal side effects of allogeneic BMT, may occur $[5,6]$.

We have recently developed a new BMT method, intrabone marrow (IBM)-BMT, in which bone marrow cells (BMCs) are directly injected into the bone marrow cavity [7]. IBM-BMT results in a reduced incidence of GVHD and greater engraftment of donor cells, including mesenchymal stem cells, than the conventional intravenous method $[8,9]$.

We have also developed a BMT method in conjunction with thymus transplantation (TT). The combination of BMT and TT is effective in restoring donor-derived T cell function in aged, chimeric-resistant, tumor-bearing, supralethally irradiated, and low-dose irradiated mice and also in mice injected with a small number of BMCs [10-13]. We have further demonstrated that IBM-BMT + TT is effective for tumor regression and long-term survival [14,15].

However, hematopoietic cell and thymic functions differ with age. The proliferative activity of $\mathrm{T}$ cells from the fetal and newborn thymus is much higher than in those from adults $[16,17]$, whereas the level of cytokine production increases with age [18]. In this regard, we have recently found that supralethally irradiated mice are rescued by [newborn liver cell transplantation (NLT) + newborn TT (NTT)] more efficiently than by [BMT + adult TT (ATT)] or [fetal liver cell transplantation (FLT) + fetal TT (FTT)] [12]. In the present study, we investigated the most effective donor age for [hematopoietic stem cell transplantation (HSCT) + TT] for tumor-bearing hosts.

\section{Materials and Methods}

Mice

Female 6- to 8-week-old, newborn ( $\leq 48 \mathrm{~h}$ after birth), and fetal day-16 C57BL/6 (B6) $\left(\mathrm{H}-2^{\mathrm{b}}\right)$ and BALB/c $\left(\mathrm{H}-2^{\mathrm{d}}\right)$ mice

\footnotetext{
${ }^{1}$ First Department of Pathology, ${ }^{3}$ Department of Stem Cell Disorders, Kansai Medical University, Osaka, Japan

${ }^{2}$ Department of Pediatrics, Nanfang Hospital, Guangzhou, China.

${ }^{4}$ JIMRO Co., Ltd., Gunma, Japan.

*These 2 authors contributed equally to this study.
} 
were obtained from Shimizu Laboratory Supplies and maintained until use in our animal facilities under specific pathogen-free conditions. All protocols for these animal experiments were performed in accordance with the Guidelines for Animal Experimentation, Kansai Medical University, and received approval from the Committee of Animal Experiments.

\section{Cell lines}

Meth A cells $\left(\mathrm{H}-2^{\mathrm{d}}\right)$ were derived from methylcholanthrene-induced sarcomas in BALB/c mice [14]. Cells were maintained in RPMI 1640 medium supplemented with 10\% fetal calf serum with antibiotics.

\section{Inoculation of tumor cells}

One day before the inoculation of tumor cells, the recipients (BALB/c mice) underwent total-body irradiation (3Gy) using a ${ }^{137} \mathrm{Cs}$ irradiator (Gammacell 40 Exactor; MDS Nordion International). The next day, $2 \times 10^{6}$ Meth A cells were subcutaneously inoculated into the right flank of these mice.

\section{HSCT and TT}

Recipient BALB/c mice with tumors were irradiated (8 Gy) using the ${ }^{137} \mathrm{Cs}$ irradiator 1 day before HSCT. The next day, these mice were injected with $1 \times 10^{7}$ B6 HSCs using the IBM-BMT method. Briefly, single-cell suspensions $\left(1 \times 10^{7}\right)$ were directly injected into the bone marrow cavity of the tibia [7]. BMCs were collected from the femurs and tibias of 6- to 8-week-old B6 mice. Newborn and fetal livers were obtained from the mice. Single-cell suspensions as newborn liver cells and fetal liver cells were prepared for use of HSCs [10]. For TT, AT, NT, and FT tissues were obtained from mice of the above ages. One quarter of the AT, or one NT or one FT, were simultaneously transplanted under the renal capsule in some recipients with HSCT. TT alone was also performed in other mice.

\section{Histology}

Histological studies were performed in the liver, intestine (for evaluation of GVHD), and engrafted thymus from the recipients 4 weeks after the BMT. The tissues were fixed in $10 \%$ formaldehyde and embedded in paraffin. Serial tissue sections ( $4 \mu \mathrm{m}$ thick) were prepared and stained using hematoxylin and eosin.

\section{Analysis of surface marker antigens and intracellular FoxP3 and cytokines by flow cytometry}

Surface markers on lymphocytes from the spleen were analyzed by 3-color fluorescence staining using a FACScan system (BD Pharmingen, Franklin Lakes, NJ). Fluorescein isothiocyanate (FITC)-conjugated anti-H-2K ${ }^{\mathrm{b}}$ (BD Pharmingen) $\mathrm{mAbs}$ and phycoerythrin (PE)-conjugated anti- $\mathrm{H}-2 \mathrm{~K}^{\mathrm{d}}$ $\mathrm{mAbs}$ were used to determine chimerism. FITC, PE, or biotinconjugated CD4, CD8, B220, Gr-1, CD11b, CD44, or CD62L (BD Pharmingen) were used to analyze spleen cell subsets. Avidin-PE-Cy5 (Dako) was used as the third color in the avidin/biotin system. Intracytoplasmic FoxP3 staining was performed using an eBioscience FITC-anti mouse/rat FoxP3 staining set in accordance with the manufacturer's instructions (eBioscience, San Diego, CA). Intracellular cytokines [interleukin 2 (IL-2), IL-4, IL-10, IL-17, interferon $\gamma$ (IFN- $\gamma$ ), and tumor necrosis factor] were detected using an Intracellular Cytokine Staining Kit in accordance with the manufacturer's instructions (Becton Dickinson).

\section{Mitogen responses}

To analyze lymphocyte function, mitogen responses were examined in chimeric mice 2 months after the transplantation. For mitogen response, a total of $2 \times 10^{5}$ splenocytes collected from chimeric mice and nontreated B6 and BALB/c mice as responders were plated in 96-well flat-bottomed plates (Corning Glass Works, Corning, NY) containing $200 \mu \mathrm{L}$ of RPMI 1640 medium (Nissui Seiyaku, Tokyo, Japan) supplemented with $2 \mu \mathrm{L}$ of glutamine (Wako Pure Chemicals, Osaka, Japan), penicillin $(100 \mathrm{U} / \mathrm{mL})$, streptomycin $(100 \mu \mathrm{g} / \mathrm{mL})$, and $10 \%$ heatinactivated fetal calf serum. For mitogen responses, responder cells were incubated with $2.5 \mu \mathrm{g} / \mathrm{mL}$ of concanavalin A (ConA) (Calbiochem, San Diego, CA) or $25 \mu \mathrm{g} / \mathrm{mL}$ of lipopolysaccharide (LPS) (Difco Laboratories, Sparks, MI) for 48 or $72 \mathrm{~h}$. During the last $18 \mathrm{~h}$ of the culture period, $20 \mathrm{~mL}$ of $0.5 \mu \mathrm{Ci}^{3} \mathrm{H}$ thymidine $\left({ }^{3} \mathrm{H}-\mathrm{TdR}\right.$; New England Nuclear) was introduced. Incorporation of ${ }^{3} \mathrm{H}-\mathrm{TdR}$ was measured using Microbeta TriLux (PerkinElmer, Waltham, MA). The stimulation index was calculated as the average of ${ }^{3} \mathrm{H}-\mathrm{TdR}$ incorporation in triplicate samples of responding cells with mitogen $\beta \mathrm{H}-\mathrm{TdR}$ incorporation of responding cells in medium alone.

\section{Statistical analyses}

Nonparametric analyses (Mann-Whitney $U$-test and log rank-test) were performed using StatView software (Abacus Concepts). Values of $P<0.05$ were considered statistically significant.

\section{Results \\ Chimerism and tumor size}

To examine the effects of HSCT + TT from various ages in tumor-bearing hosts, we performed BMT $(n=8)$, BMT + ATT $(n=10)$, NLT $(n=10), \mathrm{NLT}+\mathrm{NTT}(n=8)$, FLT $(n=10)$, or FLT + FTT $(n=8)$ in mice-bearing Meth-A sarcomas measuring $>0.5 \mathrm{~cm}^{2}$. All mice treated with HSCT showed donor BMC-derived chimerism (data not shown). In analyses of tumor size, all of the mice treated with HSCT showed significant tumor regression compared with the nontreated controls $(n=9)$ (Fig. 1A, B). Interestingly, the tumors were significantly smaller in the mice treated with HSCT + TT than in those treated with HSCT alone in all age groups (Fig. 1B). The mice treated with either NLT + NTT or FLT + FTT showed the greatest degree of tumor regression (Fig. 1A).

\section{Survival period}

We also examined the survival period (Fig. 1C). As expected, nontreated control mice bearing tumors showed the shortest survival period. Similar to tumor size, survival in the mice treated with HSCT + TT was significantly prolonged compared with those treated with HSCT alone in all age groups. However, in contrast to tumor size, mice treated with NLT + NTT showed the longest survival, followed by 
A

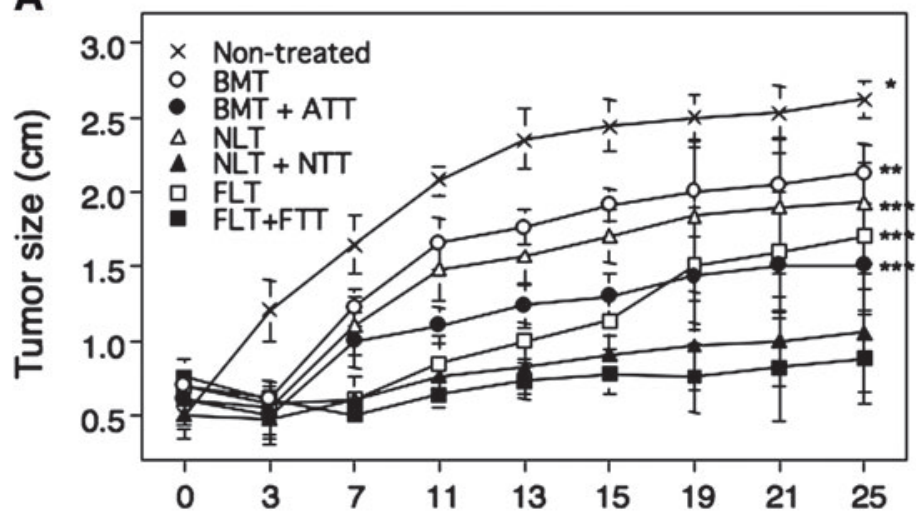

C

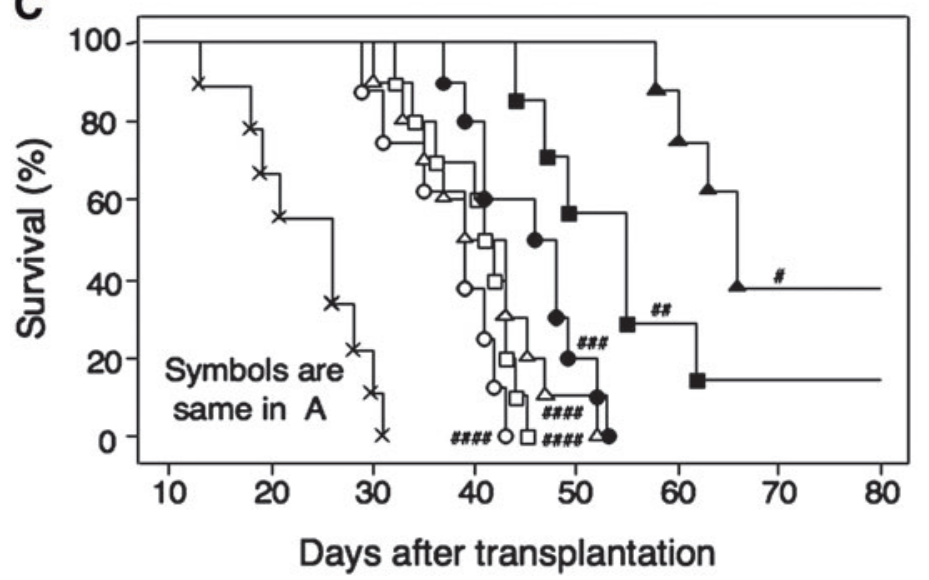

B
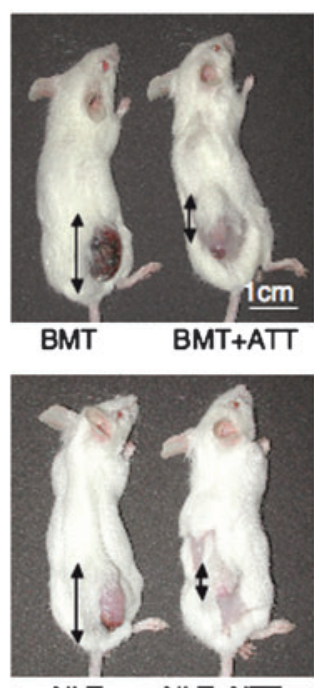

NLT NLT+NTT

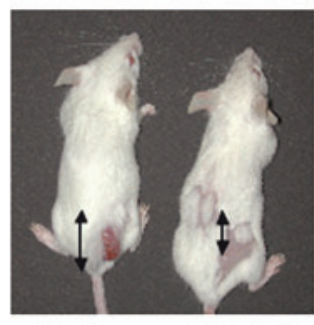

FLT

FIG. 1. Tumor size and survival rate in tumor-bearing mice treated with hematopoietic stem cell transplantation (HSCT) and thymus transplantation (TT) from various ages. Tumor size (A, B: representative data) and survival rate $(\mathbf{C})$ are shown in tumorbearing mice treated with bone marrow transplantation (BMT), BMT + adult TT (ATT), newborn liver cell transplantation (NLT), NLT + newborn TT (NTT), fetal liver cell transplantation (FLT), FLT + fetal TT (FTT), and nontreated controls. ${ }^{*} P<0.03$ compared with $\mathrm{BMT}, \mathrm{BMT}+\mathrm{ATT}, \mathrm{NLT}, \mathrm{NLT}$ NTT, FLT, and FLT+FTT. ${ }^{*} P<0.03$ compared with $\mathrm{BMT}+\mathrm{ATT}, \mathrm{NLT}+\mathrm{NTT}$, and FLT + FTT. $\quad * * * P<0.03$ compared with NLT + NTT and FLT + FTT. $\quad{ }^{\#} P<0.04$ compared with nontreated control, BMT, BMT + ATT, NLT, FLT, and FLT + FTT. ${ }^{\# \#} P<0.02$ compared with nontreated control and BMT, BMT + ATT, NLT, and FLT. ${ }^{\# \#} P<0.01$ compared with nontreated control and BMT. ${ }^{\# \# \# P<0.001}$ compared with nontreated control. Nontreated $(n=9)$,

$\operatorname{BMT}(n=8), \operatorname{BMT}+\operatorname{ATT}(n=10), \operatorname{NLT}(n=10), \operatorname{NLT}+\operatorname{NTT}(n=8), \operatorname{FLT}(n=10), \operatorname{FLT}+$ FTT $(n=8)$. Data are shown as means \pm standard deviation (SD). Double-headed arrows show tumor size.

those treated with FLT + FTT, and then those treated with BMT + ATT. All the mice treated with TT alone from any age died within 3 weeks after transplantation.

\section{Analyses of TT}

We next analyzed the thymus of the mice treated with HSCT + TT from various ages 4 weeks after transplantation.
The size was smallest in ATT, followed by NTT, but largest in FTT (Fig. 2). Histologically, although both the cortex and medular areas were clearly shown, the ratio of cortex/ medulla in TT was also smallest in ATT, followed by NTT, but largest in FTT. In analyses of thymocyte subsets, the highest percentage of $\mathrm{CD}^{+}$or $\mathrm{CD}^{+}$single-positive thymocytes was observed in ATT, followed by NTT, but lowest in FTT. Conversely, the percentages of $\mathrm{CD}^{+}$and $\mathrm{CD}^{+}$
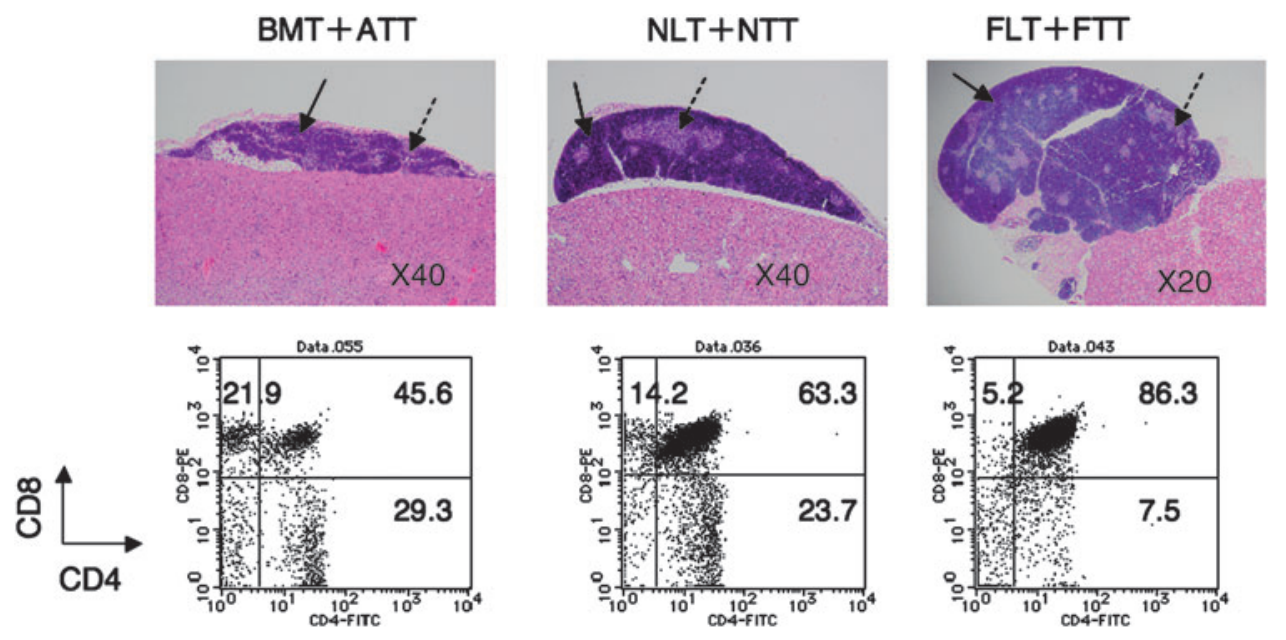

FIG. 2. Macroscopic and histological findings and FACS profiles of thymocytes in the transplanted thymus from tumor-bearing mice treated with HSCT and TT from various ages. Histological findings (upper panels, HE staining) and the FACS profiles of $\mathrm{CD}^{+}$and $\mathrm{CD}^{+}$cells in thymocytes (lower panels) from the transplanted thymus in tumor-bearing mice treated with BMT + ATT, $\mathrm{NLT}+\mathrm{NTT}$, or FLT + FTT (lower panels). Plain arrows, cortex; dotted arrows, medulla. Representative data from 4 experiments are shown. 
double-positive and $\mathrm{CD}^{-}$and $\mathrm{CD}^{-}$double-negative thymocytes were lowest in ATT, followed by NTT, but highest in FTT.

\section{Analyses of lymphocyte subsets}

We investigated donor-derived lymphocyte subsets in the spleen 4 weeks after transplantation in the mice treated with HSCT and 3 weeks in the nontreated controls due to early death. The number of $\mathrm{CD}^{+} \mathrm{T}$ cells significantly increased in the mice treated with HSCT + TT compared with those treated with HSCT alone at all ages (Fig. 3A). The numbers were highest in the mice treated with either NLT + NTT or FLT + FTT and were comparable to those of normal B6 mice. Those treated with BMT showed the lowest, although the analysis day was different from that of nontreated control. The results of CD8 ${ }^{+} \mathrm{T}$ cells were similar to those of $\mathrm{CD}^{+} \mathrm{T}$ cells except that, at all ages, they were lower than those of normal B6 mice.

The percentage of $\mathrm{FoxP}^{+}$cells in $\mathrm{CD}^{+} \mathrm{T}$ cells, which reflects the immunosuppressive activity [19], was the highest in the nontreated controls (Fig. 3B). The percentage of cells significantly decreased in the mice treated with HSCT + TT compared with those treated with HSCT alone in all age groups. However, the percentage was not different between the ages, and the level in the mice treated with HSCT + TT was comparable to that in normal B6 mice.
The number of Gr-1/Mac-1 myeloid suppressor cells, which are induced in hosts bearing cancer and inhibit immune function [20,21], was highest in nontreated control mice (Fig. 3D). It significantly decreased in the mice treated with HSCT + TT compared with those treated with HSCT alone, in all age groups. Interestingly, the mice treated with FLT or FLT + FTT showed the highest number of cells among the groups for HSCT or HSCT + TT. As expected, normal B6 mice showed only a few of these cells.

\section{Analyses of proportions of effector, central memory, and naïve $T$ cells}

$\mathrm{T}$ cells can be functionally divided into $\mathrm{CD}^{-} \mathrm{L}^{-} \mathrm{CD} 44^{-}$ naïve $\mathrm{T}$ cells and $\mathrm{CD}_{2} \mathrm{~L}^{+} \mathrm{CD} 44^{+}$central memory $(\mathrm{CM})$ and $\mathrm{CD}_{2} \mathrm{~L}^{-} \mathrm{CD} 44^{+}$effector memory (EM) cells from prestimulation to terminal differentiation $[22,23]$. We, therefore, examined the proportion of these cells in both CD4 and CD8 subsets of T cells (Fig 4). The nontreated control mice showed a significant elevation of EM T cell number but a reduced number of CM T cells in both subsets compared with B6 mice. Interestingly, the mice treated with HSCT + TT also showed significant elevation of EM T cells but a reduction of CM T cells, compared with those treated with HSCT alone. Among all mice, those treated with NLT + NTT showed the highest \% of EM T cells and the lowest \% of CM T cells in both subsets.

FIG. 3. Numbers of cells in the spleen from tumor-bearing mice treated with HSCT and TT from various ages. Numbers of $\mathrm{CD}^{+} \mathrm{T}$ cells (A), percentage of $\mathrm{FoxP}^{+}$cells in $\mathrm{CD}^{+}{ }^{+} \mathrm{T}$ cells $(\mathrm{B})$, numbers of $\mathrm{CD}^{+} \mathrm{T}$ cells $(\mathbf{C})$, and Gr-1/ CD11b cells (D) in the spleen were evaluated in tumorbearing mice treated with $\mathrm{BMT}, \quad \mathrm{BMT}+\mathrm{ATT}, \quad \mathrm{NLT}$, NLT + NTT, FLT, or FLT + FTT, nontreated controls, or B6 mice. The experiments were performed 4 weeks after transplantation in the mice treated with HSCT and 3 weeks in the nontreated controls because of early death. ${ }^{*} \mathrm{P}<0.05$. ${ }^{\#} \mathrm{P}<0.05$ compared with nontreated control, BMT, $\mathrm{BMT}+\mathrm{ATT}, \mathrm{NLT}$, or FLT. ${ }^{\# \#} P<0.03$ compared with BMT. ${ }^{{ }} P<0.05$ compared with nontreated control, BMT, $\mathrm{BMT}+\mathrm{ATT}, \quad \mathrm{NLT}, \quad \mathrm{NLT}+$ NTT, FLT, FLT + FTT, or B6 mice. ${ }^{\S}{ } P<0.05$ compared

A

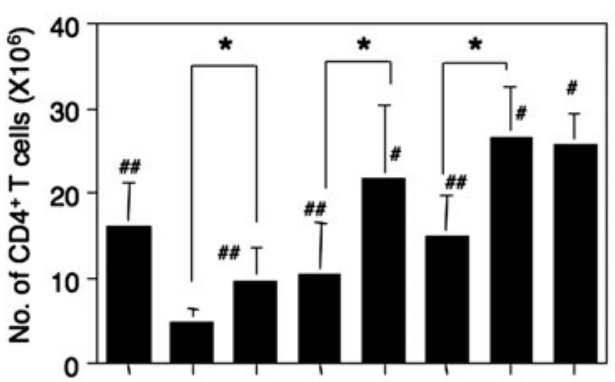

C

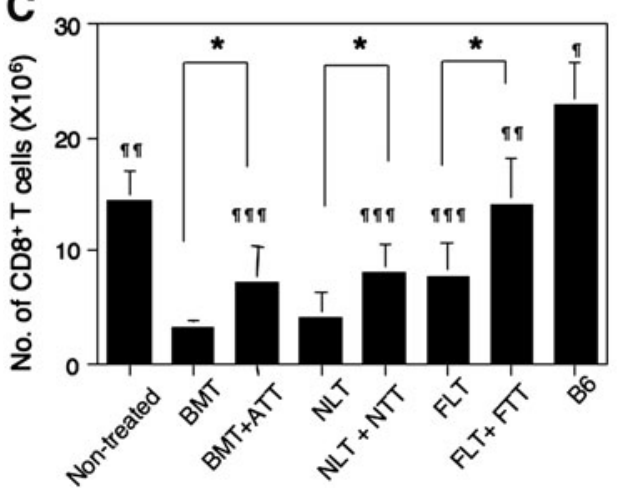

B
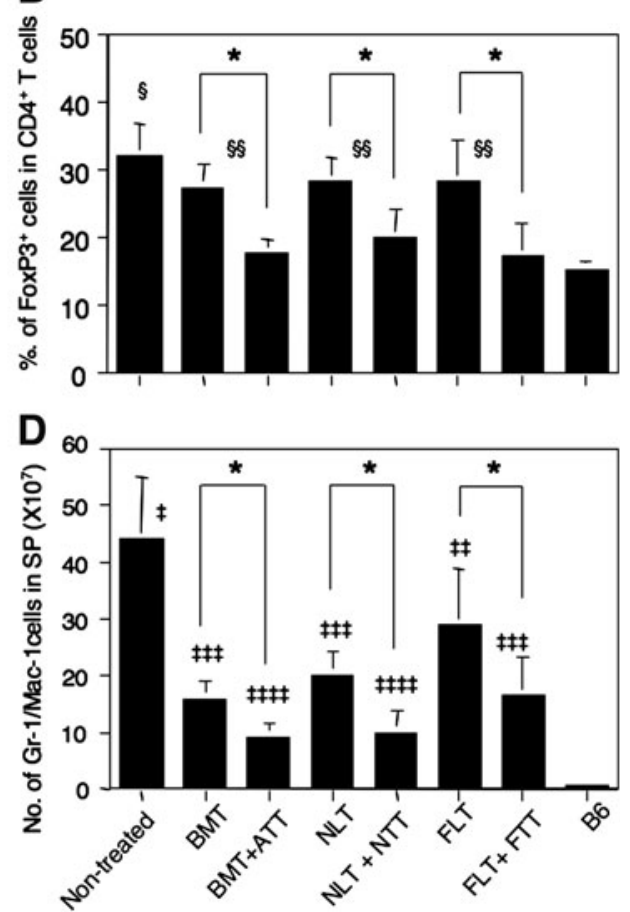
with BMT + ATT, NLT + NTT, FLT + FTT, or B6 mice. " $P<0.02$ compared with nontreated control, BMT, BMT + ATT, NLT,

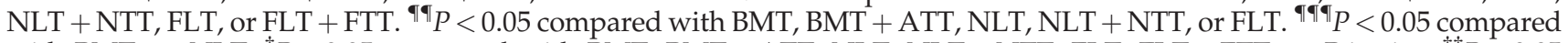
with BMT, or NLT. ${ }^{\dagger} P<0.05$ compared with BMT, BMT + ATT, NLT, NLT + NTT, FLT, FLT + FTT, or B6 mice. ${ }^{\dagger \dagger} P<0.05$ compared with BMT, BMT + ATT, NLT, NLT + NTT, FLT + FTT, or B6 mice. ${ }^{\dagger \dagger} P<0.05$ compared with BMT + ATT, NLT NTT, or B6 mice. ${ }^{\dagger \dagger} P<0.05$ compared with B6 mice. Nontreated $(n=4)$, BMT $(n=4), \operatorname{BMT}+\operatorname{ATT}(n=4)$, NLT $(n=5)$, $\mathrm{NLT}+\operatorname{NTT}(n=4), \operatorname{FLT}(n=5), \operatorname{FLT}+\operatorname{FTT}(n=4)$, B6 mice $(n=4)$. Data are shown as means \pm SD. 


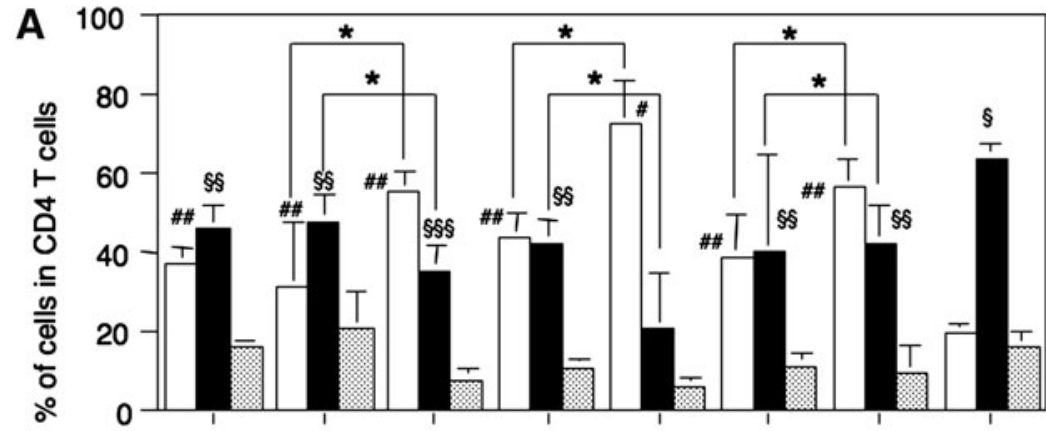

B

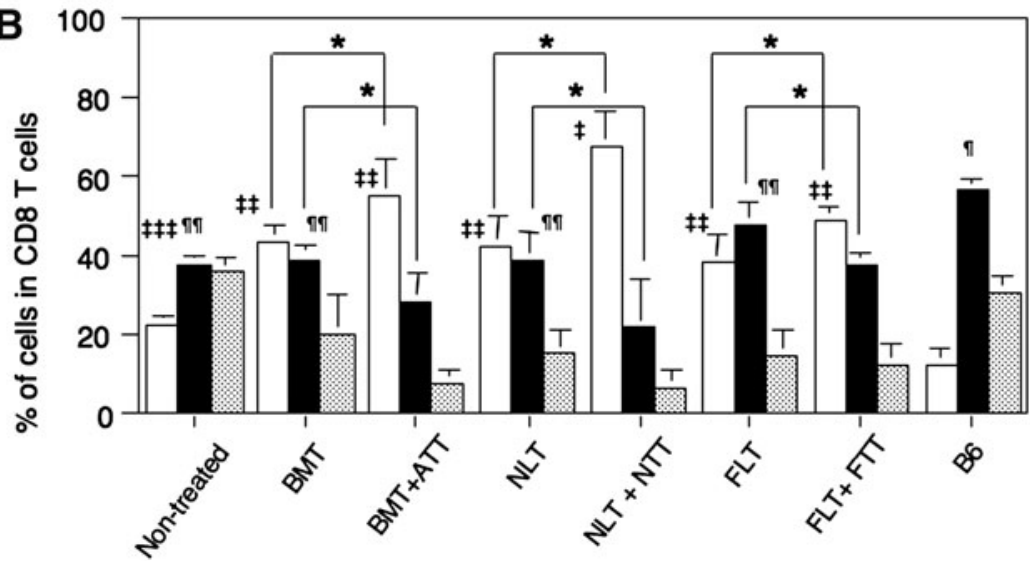

FIG. 4. Proportions of effector memory (EM), central memory $(\mathrm{CM})$, and naïve $\mathrm{T}$ cells from tumor-bearing mice treated with HSCT and TT from various ages. Percentages of $\mathrm{CD}^{-} \mathrm{L}^{-} \mathrm{CD} 44^{+} \mathrm{EM}$, $\mathrm{CD}^{2} 2 \mathrm{~L}^{+} \mathrm{CD}_{44}{ }^{+} \mathrm{CM}$, and CD62L ${ }^{-} \mathrm{CD}_{44^{-}}$naïve $\mathrm{T}$ cells in $\mathrm{CD}^{+}$(A) and $\mathrm{CD}^{+}$(B) subsets were analyzed in the spleens from tumor-bearing mice treated with BMT, BMT+ ATT, NLT, NLT + NTT, FLT, or FLT + FTT, or nontreated control, or B6 mice. Analyses were performed at the same time for the experiment of Fig. 3. ${ }^{*} P<0.05 .{ }^{\#} P<0.05$ compared with nontreated control, BMT, BMT + ATT, NLT, FLT, FLT + FTT, or B6 mice. ${ }^{\# \#} P<0.03$ compared with B6 mice. ${ }^{\S} P<0.03$ compared with nontreated control, $\mathrm{BMT}, \mathrm{BMT}+\mathrm{ATT}, \mathrm{NLT}$, or NLT + NTT, FLT, or FLT + FTT. ${ }^{\S} P<0.03$ compared with $\mathrm{BMT}+\mathrm{ATT}$, or NLT + NTT. $\S \S \S P<0.03$ compared with NLT + NTT. ${ }^{\dagger} P<0.03$ compared with nontreated control, BMT, BMT + ATT, NLT, FLT, FLT + FTT, or B6 mice. ${ }^{\dagger \dagger} P<0.03$ compared with nontreated control and B6 mice. ${ }^{\dagger \dagger} P<0.03$ compared with B6 mice. ${ }^{\top} P<0.03$ compared with nontreated control, BMT, BMT + ATT, NLT, NLT + NTT, FLT, or FLT + FTT. ${ }^{\top} P<0.03$ compared with BMT + ATT, NLT + FTT, or FLT + FTT. Nontreated $(n=4)$, BMT $(n=4), \operatorname{BMT}+\operatorname{ATT}(n=4), \operatorname{NLT}(n=5), \operatorname{NLT}+\operatorname{NTT}(n=4), \operatorname{FLT}(n=5), \operatorname{FLT}+\operatorname{FTT}(n=4)$, and B6 mice $(n=4)$. Data are shown as means \pm SD.

\section{Analyses of lymphocyte function and cytokine production}

Finally, we examined lymphocyte function by monitoring mitogen response (ConA for T cells and LPS for B cells) and cytokine production. The mice treated with $\mathrm{HSCT}+\mathrm{TT}$ showed a significantly elevated response to ConA but not LPS, compared with those treated with HSCT alone and with the nontreated controls, although the levels did not reach those of normal B6 mice (Fig. 5A). The stimulator index in mice treated with either FLT + FTT or NLT + NTT was significantly higher than in those treated with BMT + ATT.

The mice treated with HSCT + TT showed significantly elevated production of IL-2 and IFN- $\gamma$ compared with those treated with HSCT alone (Fig. 5B). However, the production of IL-2 did not significantly differ between those treated with HSCT + TT in all age groups, and the levels were comparable to that in normal B6 mice. In contrast, the production of IFN- $\gamma$ was highest in the mice treated with NLT + NTT, and the levels were comparable to that in normal B6 mice. IL-4, IL-10, IL-17, and tumor necrosis factor levels were almost undetectable and did not correlate with any clinical findings (survival and tumor regression). The above results are summarized in Table 1 . Those treated with NLT + NTT showed the highest T cell numbers and functions.

\section{Discussion}

In the present study, we have examined the effects of allogeneic HSCT + TT from various ages on tumor-bearing hosts. Although the mice treated with all types of HSCT + TT showed more tumor regression with prolonged survival compared with those treated with HSCT alone, those treated with NLT + NTT or FLT + FTT showed the best regression. The mice treated with NLT + NTT showed a longer survival period than those treated with FLT + FTT. Those treated with all types of HSCT + TT showed higher numbers of both $\mathrm{CD}^{+}$and $\mathrm{CD} 8^{+} \mathrm{T}$ cells and percentage of EM cells and a lower number of $\mathrm{Gr}-1^{+} / \mathrm{CD}_{11} \mathrm{~b}^{+}$myeloid suppressor cells and percentage of $\mathrm{FoxP}^{+} / \mathrm{CD} 4 \mathrm{~T}$ cells than those treated with HSCT alone. Interestingly, those treated with NLT + NTT showed the highest $\mathrm{T}$ cell numbers and lowest suppressor cell numbers. These findings indicated that HSCT + TT is effective for hosts with cancer and that the combination of NLT + NTT is best at all ages.

Although the mice treated with HSCT + TT showed greater tumor regression with more prolonged survival than those treated with HSCT alone, these results differed according to ages. In all age groups, FLT + FTT or NLT + NTT showed the best results, and the latter showed the longest survival period. Since there were no differences with HSCT alone in any age group, the transplanted thymus may also play an important role. Although the liver stem cells may 
FIG. 5. Mitogen responses and percentages of cytokineproducing cells in the spleens from tumor-bearing mice treated with HSCT and TT from various ages. Mitogen responses: concanavalin A (ConA) and lipopolysaccharide (LPS) (A) and percentages of cytokine-producing cells (B) in the spleen were evaluated in the spleens from tumor-bearing mice treated with BMT, BMT ATT, NLT, NLT + NTT, FLT, or FLT + FTT, or nontreated control, or B6 mice. Analyses were performed at the same time for the experiment of Fig. 3. ${ }^{*} P<0.05$. ${ }^{\#} P<0.03$ compared with nontreated control, BMT, BMT + ATT, NLT, NLT NTT, FLT, or FLT + FTT. ${ }^{\# \#} P<0.03$ compared with nontreated control, BMT, BMT + ATT, NLT, or FLT. ${ }^{\# \#} P<0.03$ compared with nontreated control, BMT, NLT, or FLT. ${ }^{\dagger} P<0.03$ compared with nontreated control, BMT, or NLT, or FLT. ${ }^{{ }} \mathrm{P}<0.03$ compared with nontreated control, BMT, $\mathrm{BMT}+\mathrm{ATT}, \mathrm{NLT}, \mathrm{FLT}$, or FLT + FTT. ${ }^{\S} \mathrm{P}<0.05$ compared with nontreated control, BMT, NLT, or FLT. Nontreated $(n=4), \mathrm{BMT}$ $(n=4), \mathrm{BMT}+\mathrm{ATT}(n=4), \mathrm{NLT}(n=5), \mathrm{NLT}+\mathrm{NTT}(n=4), \mathrm{FLT}(n=5), \mathrm{FLT}+\mathrm{FTT}(n=4), \mathrm{B} 6$ mice $(n=4)$. Data are shown as means \pm SD.

influence the results in FLT and/or NLT compared with BMT, the transplanted thymus plays a critical role in the further effects with the elevated T cell function.

We, therefore, analyzed the transplanted thymus. Interestingly, although ATT grafts showed some atrophic features after transplantation, FTT grafts showed marked growth, and NTT grafts showed intermediate growth. Similarly, $\mathrm{CD}^{+}$and $\mathrm{CD}^{+}$subsets in the thymocytes of ATT grafts shifted to being relatively mature, whereas those in FTT grafts shifted to being relatively immature, and those in NTT grafts were intermediate. These findings suggested that their characteristics of age-related proliferative activity and maturity may also reflect the transplanted thymus. This may also influence the number, pheno type and function of splenic T cells, as discussed later.

We next analyzed lymphocyte subsets in the spleen from all chimeric mice. The numbers of both $\mathrm{CD}^{+}$and $\mathrm{CD}^{+} \mathrm{T}$ cells significantly increased in the mice treated with HSCT

Table 1. Summary of Data in All Groups ${ }^{a}$

\begin{tabular}{|c|c|c|c|c|c|c|}
\hline Factors & $B M T$ & $B M T+A T T$ & NLT & $N L T+N T T$ & FLT & $F L T+F T T$ \\
\hline CD4 T cells & $\downarrow$ & $\rightarrow$ & $\rightarrow$ & $\uparrow$ & $\rightarrow$ & $\uparrow$ \\
\hline CD8 T cells & $\downarrow$ & $\rightarrow$ & $\rightarrow$ & $\uparrow$ & $\uparrow$ & $\uparrow \uparrow$ \\
\hline$\%$ of FoxP3 in CD4 T cells & $\downarrow$ & $\downarrow \downarrow$ & $\downarrow$ & $\downarrow \downarrow$ & $\downarrow$ & $\downarrow \downarrow$ \\
\hline Gr-1/Mac-1 & $\downarrow \downarrow$ & $\downarrow \downarrow \downarrow$ & $\downarrow \downarrow$ & $\downarrow \downarrow \downarrow$ & $\downarrow$ & $\downarrow \downarrow$ \\
\hline$\%$ of EM CD4 T cells & $\stackrel{\downarrow \downarrow}{\rightarrow}$ & $\begin{array}{c}\downarrow \downarrow \downarrow \\
\uparrow \\
\uparrow\end{array}$ & $\stackrel{\downarrow \downarrow}{\rightarrow}$ & $\uparrow \uparrow$ & $\stackrel{\downarrow}{\rightarrow}$ & 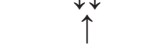 \\
\hline$\%$ of EM CD8 T cells & $\uparrow$ & $\uparrow \uparrow$ & $\uparrow$ & $\uparrow \uparrow \uparrow$ & $\uparrow$ & $\uparrow \uparrow$ \\
\hline ConA & $\rightarrow$ & $\uparrow$ & $\rightarrow$ & $\uparrow \uparrow$ & $\rightarrow$ & $\uparrow \uparrow$ \\
\hline IL-2 & $\rightarrow$ & $\uparrow$ & $\rightarrow$ & $\uparrow$ & $\rightarrow$ & $\uparrow$ \\
\hline IFN- $\gamma$ & $\rightarrow$ & $\uparrow$ & $\rightarrow$ & $\uparrow \uparrow$ & $\rightarrow$ & $\uparrow$ \\
\hline
\end{tabular}

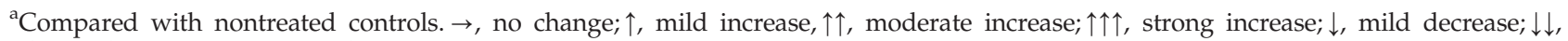
moderate decrease; $\downarrow \downarrow \downarrow$, strong decrease.

ATT, adult thymus transplantation; BMT, bone marrow transplantation; ConA, concanavalin A; EM, effector memory; FLT, fetal liver cell transplantation; FTT, fetal thymus transplantation; IFN- $\gamma$, interferon $\gamma$; IL-2, interleukin 2; NLT, newborn liver cell transplantation; NTT, newborn thymus transplantation. 
TT, compared with those treated with HSCT alone. The mice treated with FLT + FTT or NLT + NTT showed the highest numbers, suggesting that these $\mathrm{T}$ cells may play an important role in prolonging survival and tumor regression. The elevated $\mathrm{T}$ cell number may be related to the high proliferative activity of NT or FT. The percentage of FoxP3 ${ }^{+}$cells in $\mathrm{CD}^{+}{ }^{+} \mathrm{T}$ cells significantly decreased in the mice treated with HSCT + TT, compared with those treated with HSCT alone, and the levels were almost the same in all age groups. These findings indicated that FoxP3 ${ }^{-} \mathrm{CD}^{+}$effector cells are dominantly supplied from TT grafts compared with FoxP3 ${ }^{+} \mathrm{CD} 4^{+}$ regulatory $\mathrm{T}$ cells in the allo-environment [14]. However, the level was no less than that in normal mice. Since the low level of regulatory $\mathrm{T}$ cells was strongly associated with the induction of GVHD $[19,24]$, the relatively elevated levels in the mice treated with HSCT + TT may lead to the prevention or inhibition of GVHD but not of graft versus tumor [25]. Therefore, we did not observe any obvious findings of GVHD in any of the mice treated with HSCT + TT in this study, although some GVHD and a related loss of FoxP3 ${ }^{+} \mathrm{CD}^{+}$regulatory $\mathrm{T}$ cells were found in the intensive regimen of a previous study [14].

We have also found that the number of Gr-1/CD11b myeloid suppressor cells is also significantly reduced in mice treated with HSCT + TT compared with those treated with HSCT alone, as previously reported [15]. This may also contribute, at least in part, to the longer survival in the former group compared with the latter. However, the mice treated with FLT or FLT + FTT showed the highest cell numbers of myeloid suppressor cells in the HSCT or HSCT + TT groups. Since the tumor burden was the same in both NLT + NTT and FLT + FTT [26] and it induces the cells, the greater number of myeloid suppressor cells in fetal liver cells should be responsible for the difference in survival.

The percentages of EM T cells, which were derived from $\mathrm{CM}$ cells with terminal differentiation and had the strongest immune activity [22,23], increased in all mice with tumors, in contrast to those without tumors. In addition, the mice treated with HSCT + TT also showed a higher percentage of EM cells than those with HSCT alone. Therefore, the elevation of cell numbers may also be partially induced from TT. Interestingly, the percentage of EM cells was highest in NLT + NTT in both CD4 and CD8 T cell subsets. Although the detailed mechanism remains unknown, the $\mathrm{T}$ cells from NTT were more proliferative than ATT and more functional than FTT, and this may have led to the high expansion activity of these cells.

The mice treated with HSCT + TT showed significantly greater $\mathrm{T}$ cell function (ConA response) than those treated with HSCT alone or the nontreated controls. The mice treated with either FLT + FTT or NLT + NTT showed the greatest ConA response. However, it should be noted that IFN- $\gamma$ production in those treated with NLT + NTT was highest among all the mice in the present study. This may have been because of the low numbers of Gr-1/Mac-1 cells and/or high numbers of EM T cells, in which IFN- $\gamma$ is produced at the highest levels in these mice [18,22].

Thus, the results of the present study indicated that additional TT is effective in HSCT from all ages in tumorbearing hosts and that the combination of NLT + NTT shows the greatest effect. This may have led to the highest $\mathrm{T}$ cell function with high levels of IFN- $\gamma$ production in these mice.
Although the detailed mechanism is still unknown and needs further study, the thymocytes from the day-16 FT showed a high proliferative activity with little $\mathrm{T}$ cell receptor expression, whereas those from the AT showed a low proliferative activity with steady $\mathrm{T}$ cell receptor expression [27]. Those from NT may have an intermediate character, a relative high proliferative activity with specific responses, leading to a favorable effect for the tumor regression and prolonged survival.

Although ethically and technically it may be difficult to obtain newborn human thymus tissue from various donor ages, such tissue could be obtained from patients with congenital heart disease or from aborted fetuses, as previously discussed [28,29]. In addition, we have very recently found that third-party FT can be used to induce tolerance, although it is limited in hosts with low thymic function [30]; otherwise, the grafted thymus should be rejected. In addition, a method of regenerating the thymus has also been developed [31-34]. These findings suggest that HSCT + TT will become a viable strategy for the treatment of malignant tumors in humans.

\section{Acknowledgments}

This work was supported by a grant from Haiteku Research Center of the Ministry of Education, a grant from the Millennium Program of the Ministry of Education, Culture, Sports, Science, and Technology, a grant from the Science Frontier Program of the Ministry of Education, Culture, Sports, Science, and Technology, a grant from The 21st Century Center of Excellence Program of the Ministry of Education, Culture, Sports, Science, and Technology, a Research Grant B from Kansai Medical University, Health and Labor Sciences research grants (Research on Human Genome, Tissue Engineering Food Biotechnology), a grant from the Department of Transplantation for Regeneration Therapy (sponsored by Otsuka Pharmaceutical Co., Ltd.), a grant from the Molecular Medical Science Institute (Otsuka Pharmaceutical Co., Ltd.), and a grant from Japan Immunoresearch Laboratories Co., Ltd. (JIMRO). We wish to thank Ms. Y. Tokuyama and Ms. A. Kitajima for their technical assistance and Mr. Hilary Eastwick-Field and Ms. K. Ando for their help in the preparation of the manuscript.

\section{Author Disclosure Statement}

All authors state that no competing financial interests exist.

\section{References}

1. Imamura M, S Asano, M Harada, Y Ikeda, K Kato, S Kato, K Kawa, S Kojima, Y Morishima, Y Morishita, T Nakahata, J Okamura, S Okamoto, S Shiobara, M Tanimoto, M Tsuchida, Y Atsuta, K Yamamoto, J Tanaka, N Hamajima and Y Kodera. (2006). Current status of hematopoietic cell transplantation for adult patients with hematologic diseases and solid tumors in Japan. Int J Hematol 83:164-178.

2. Ueno NT, JD Rizzo, T Demirer, YC Cheng, U Hegenbart, MJ Zhang, M Bregni, A Carella, D Blaise, A Bashey, JD Bitran, BJ Bolwell, GJ Elfenbein, KK Fields, CO Freytes, RP Gale, HM Lazarus, RE Champlin, PJ Stiff and D Niederwieser. (2008). Allogeneic hematopoietic cell transplantation for metastatic breast cancer. Bone Marrow Transplant 41:537545. 
3. Barkholt L, M Bregni, M Remberger, D Blaise, J Peccatori, G Massenkeil, P Pedrazzoli, A Zambelli, JO Bay, S Francois, R Martino, C Bengala, M Brune, S Lenhoff, A Porcellini, M Falda, S Siena, T Demirer, D Niederwieser and O Ringdén. (2006). Allogeneic haematopoietic stem cell transplantation for metastatic renal carcinoma in Europe. Ann Oncol 17:1134-1140.

4. Bay JO, J Fleury, B Choufi, O Tournilhac, C Vincent, C Bailly, J Dauplat, P Viens, C Faucher and D Blaise. (2002). Allogeneic hematopoietic stem cell transplantation in ovarian carcinoma: results of five patients. Bone Marrow Transplant 30:95-102.

5. Chao NJ. (1997). Graft-versus-host disease. The view point from the donor T cell. Biol Blood Marrow Transplant 3:1-10.

6. Goulmy E, R Schipper, E Blokland and Falkenburg F. (1996). Mismatches of minor histocompatibility antigens between HLA-identical donors and recipients and the development of graft-versus-host-disease after bone marrow transplantation. N Engl J Med 334:281-285.

7. Kushida T, M Inaba, H Hisha, N Ichioka, T Esumi, R Ogawa, H Iida and S Ikehara. (2001). Intra-bone marrow injection of allogeneic bone marrow cells: a powerful new strategy for treatment of intractable autoimmune diseases in MRL/lpr mice. Blood 97:3292-3299.

8. Ikehara S. (2008). A novel method of bone marrow transplantation (BMT) for intractable autoimmune diseases. J Autoimmun 30:108-113.

9. Nakamura K, M Inaba, K Sugiura, T Yoshimura, AH Kwon, Y Kamiyama and S Ikehara. (2004). Enhancement of allogeneic hematopoietic stem cell engraftment and prevention of graft-versus-host diseases (GvHD) by intra-bone marrowbone marrow transplantation plus donor lymphocyte infusion. Stem Cells 22:125-134.

10. Hosaka N, M Nose, M Kyogoku, N Nagata, S Miyashima, RA Good and S Ikehara. (1996). Thymus transplantation, a critical factor for correction of autoimmune disease in aging MRL/+mice. Proc Natl Acad Sci U S A 93:85588562 .

11. Hosaka N, T Ryu, T Miyake, et al. (2007). Treatment of autoimmune diseases in MRL/lpr mice by allogeneic bone marrow transplantation plus adult thymus transplantation. Clin Exp Immunol 147:555-663.

12. Ryu T, N Hosaka, T Miyake, W Cui, T Nishida, T Takaki, M Li, K Kawamoto and S Ikehara. (2008). Transplantation of newborn thymus plus hematopoietic stem cells can rescue supralethal irradiated mice. Bone Marrow Transplant 41: 659-666.

13. Nishida T, N Hosaka, T Takaki, T Miyake, W Cui, M Inaba, H Kinoshita, T Matsuda and S Ikehara. (2009). Allogeneic intra-BM-BMT plus adult thymus transplantation from same donor has benefits for long-term survival even after sublethal irradiation or low-dose BM cell injection. Bone Marrow Transplant 43:829-837.

14. Miyake T, N Hosaka, W Cui, et al. (2009). Adult thymus transplantation with allogeneic intra-bone marrow-bone marrow transplantation from same donor induces high thymopoiesis, mild graft-versus-host reaction and strong graft-versus-tumour effects. Immunology 126:552-564.

15. Hosaka N, W Cui, Y Zhang, T Takaki, M Inaba and Ikehara S. (2010). Prolonged survival in mice with advanced tumors treated with syngeneic or allogeneic intra-bone marrow-bone marrow transplantation plus fetal thymus transplantation. Cancer Immunol Immunother 59:11211130 .
16. Adkins B, T Williamson, $\mathrm{P}$ Guevara and $\mathrm{Y}$ Bu. (2003). Murine neonatal lymphocytes show rapid early cell cycle entry and cell division. J Immunol 170:4548-4556.

17. Adkins B. (2003). Peripheral CD4 ${ }^{+}$lymphocytes derived from fetal versus adult thymic precursors differ phenotypically and functionally. J Immunol 171:5157-5164.

18. Ernst DN, WO Weigle, DJ Noonan, DN McQuitty and Hobbs MV. (1993). The age-associated increase in IFNgamma synthesis by mouse CD8 $+\mathrm{T}$ cells correlates with shifts in the frequencies of cell subsets defined by membrane CD44, CD45RB, 3G11, and MEL-14 expression. J Immunol 151:575-587.

19. Miura Y, CJ Thoburn, EC Bright, S Arai and AD Hess. (2004). Association of Foxp3 regulatory gene expression with graft-versus-host disease. Blood 104:2187-2193.

20. Bronte V, E Apolloni, A Cabrelle, R Ronca, P Serafini, P Zamboni, NP Restifo and P Zanovello. (2000). Identification of a CD11b $(+) / \mathrm{Gr}-1(+) / \mathrm{CD} 31(+)$ myeloid progenitor capable of activating or suppressing CD8(+) T cells. Blood 96: 3838-3846.

21. Kusmartsev SA, Y Li and SH Chen. (2000). Gr-1+ myeloid cells derived from tumor-bearing mice inhibit primary $\mathrm{T}$ cell activation induced through CD3/CD28 costimulation. J Immunol 165:779-785.

22. Sallusto F, D Lenig, R Förster, M Lipp and A Lanzavecchia. (1999). Two subsets of memory T lymphocytes with distinct homing potentials and effector functions. Nature 401:708712 .

23. Blander JM, DB Sant'Angelo, D Metz, SW Kim, RA Flavell, K Bottomly and CA Janeway Jr. (2003). A pool of central memory-like CD4 T cells contains effector memory precursors. J Immunol 17:2940-2948.

24. Hoffmann P, J Ermann, M Edinger, CG Fathman and S Strober. (2002). Donor-type CD4(+)CD25(+) regulatory $\mathrm{T}$ cells suppress lethal acute graft-versus-host disease after allogeneic bone marrow transplantation. J Exp Med 196:389399.

25. Edinger M, P Hoffmann, J Ermann, K Drago, CG Fathman, S Strober and RS Negrin. (2003). CD4+CD25+ regulatory T cells preserve graft-versus-tumor activity while inhibiting graft-versus-host disease after bone marrow transplantation. Nat Med 9:1144-1150.

26. Xiang X, A Poliakov, C Liu, Y Liu, ZB Deng, J Wang, Z Cheng, SV Shah, GJ Wang, L Zhang, WE Grizzle, J Mobley and HG Zhang. (2009). Induction of myeloid-derived suppressor cells by tumor exosomes. Int J Cancer 124:26212633.

27. Bluestone JA, D Pardoll, SO Sharrow and BJ Fowlkes. (1987). Characterization of murine thymocytes with CD3-associated T-cell receptor structures. Nature 326:82-84.

28. Markert ML, A Boeck, LP Hale, AL Kloster and TM McLaughlin. (1999). Transplantation of thymus tissue in complete DiGeorge syndrome. N Engl J Med 341:11801189.

29. Markert ML, CB Hicks, JA Bartlett and JL Harmon. (2000). Effect of highly active antiretroviral therapy and thymic transplantation on immunoreconstitution in HIV infection. AIDS Res Hum Retroviruses 16:403-413.

30. Cui W, N Hosaka, T Miyake, X Wang, K Guo, Y Cui, Q Li, C Song, W Feng, Q Li, T Takaki, T Nishida, M Inaba and S Ikehara. (2008). Analysis of tolerance induction using triple chimeric mice: MHC-disparate thymus, hemopoietic cells and microenvironment. Transplantation 85: 1151-1158. 
31. Zhang L, L Sun, and Y Zhao. (2007). Thymic epithelial progenitor cells and thymus regeneration: an update. Cell Res 17:50-55.

32. Takaki T, N Hosaka, T Miyake, W Cui, T Nishida, M Inaba and S Ikehara. (2008). Presence of donor-derived thymic epithelial cells in [B6 $\rightarrow$ MRL/lpr] mice after allogeneic intrabone marrow-bone marrow transplantation (IBM-BMT). J Autoimmun 31:408-415.

33. Lai L and J Jin. (2009). Generation of thymic epithelial cell progenitors by mouse embryonic stem cells. Stem Cells 27: 3012-3020.

34. Jenkinson WE, A Bacon, AJ White, G Anderson and EJ Jenkinson. (2008). An epithelial progenitor pool regulates thymus growth. J Immunol 181:6101-6108.
Address correspondence to: Prof. Susumu Ikehara, M.D., Ph.D. Department of Stem Cell Disorders Kansai Medical University 10-15 Fumizono-cho, Moriguchi Osaka 570-8506

Japan

E-mail: ikehara@takii.kmu.ac.jp

Received for publication June 12, 2010

Accepted after revision July 29, 2010

Prepublished on Liebert Instant Online July 30, 2010 
